\title{
Recent and possible future trends in abortion
}

\author{
F Lafitte Department of Social Administration, University of Birmingham
}

The regularly published abortion statistics are insufficiently detailed to make it easy to assess the significance of increases or decreases in the annual number of abortions. Numbers of abortions are related only to a few broad age groups of the women at risk, the size of those age groups is not normally stated, and the age and marital status groupings employed differ from those used for comparable data about trends in child bearing.

By matching demographic data on trends in pregnancies which are deliberately terminated (abortion) and those which are not (fertility), this note attempts a) to assess the true impact of abortion among women living in England and Wales during 1973-76, and b) to consider whether the annual volume of abortions may increase over the next decade and what such an increase might signify.

Demographers assess a population's reproductive achievement - 'fertility' - by the annual rate at which women of any age (or age group) give birth to babies. Such age-specific fertility rates, measuring the output of babies per 1000 relevant women, are shown in appended Table II, section (a), for 1973-76 for three broad age groups, with married women distinguished from others.* Reproductive wastage stillbirths and spontaneous or deliberate abortions can be assessed in the same way. For the same age groups, section (b) of Table II shows the agespecific abortion rates yielded by the statistics of operations performed under the Abortion Act 1967.

These rates are among the lowest reported from non-Communist countries with comparably liberal abortion laws. ${ }^{1}$ They also appear to have reached a peak in 1973 (1974 for the non-married aged 16-19) and to have declined somewhat subsequently, with the sole exception of the small group of teenage wives who recorded a continuing slow rise. With this exception (and with the exception of girls under I6, discussed later), women are tending to resort to abortion less frequently.

It does not, however, follow that pregnant women are making diminished use of abortion. Thus, for the whole population at risk (women aged 16-49) column 9 of Table II shows a ro per cent decrease in the overall abortion rate, from ro.I abortions per 1000

*The non-married comprise unmarried and formerly married (widowed or divorced) women. women in 1973 to 9.1 in 1976 ; but it also shows a के I4 per cent decrease in fertility (from 63.5 to $54.6 \vec{\circ}$ births per 1000 women). During the 1970 s women have very substantially reducedt he rate at which $\vec{\omega}$ they become pregnant at all; and this change would in itself tend to reduce the abortion rate even if there were no reduction in the proportion of pregnancies terminated by abortion.

\section{Known pregnancy rates}

It would therefore be more instructive to relate recorded numbers of abortions, not to all women in the relevant groups, but only to those women experiencing pregnancy. The numbers of pregnancies which result in births are known. So are 9 the numbers of those terminated by lawful abortion (see Table I). Added together, these yield annual totals of known pregnancies, from which can be derived the known pregnancy rates in section (c) of Table II. The overall known pregnancy rate, col. $9 \stackrel{\square}{\unrhd}$ shows, was reduced by 13.6 per cent from 1973 to $\vec{F}$ 1976, against only a ro per cent cut in the abortion rate.

These figures take no account of unknown numbers of other pregnancies which are terminated spontaneously (miscarriages) or by illegal abortion. $₫$ The latter cannot be numerous, but miscarriages are generally thought to account for at least 15 per cent of all conceptions. In the absence of data about $\delta$ them, it is only possible to relate abortions to known

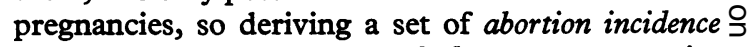
rates - i.e. percentages of known pregnancies $D$ deliberately terminated. Since the incidence of miscarriage is unlikely to fluctuate widely from year $N$ to year, trends in abortion incidence rates restricted to known pregnancies can reasonably be used to assess the true impact of abortion.

\section{Abortion incidence rates}

Abortion incidence rates so calculated are shown $\stackrel{?}{+}$ in section (d) of Table II. They do not confirm the view that the impact of abortion is declining. They suggest instead:

a) that in the major groups the rate at which known pregnancies are deliberately terminated is becoming stable, at about $5 \frac{1}{2}$ per cent for married womeno aged $20-34$ and 29 per cent for those over 34 , and 
TABLB I Women at risk, births and abortions

Thousands

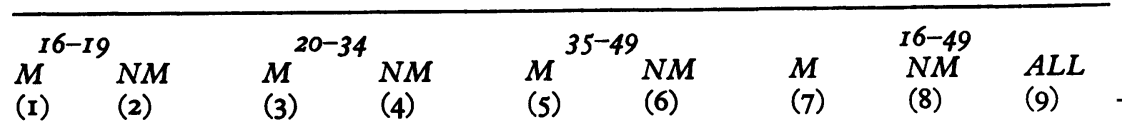

(a) WOMEN

(I) (2)

(3)

(4)

(5)

(6)

(8)

(9)

Actual numbers:

1973

I974

$148 \quad 1185$

\section{8}

$133 \quad 1210$

3788

3802

II 70

1249

II89

I 975

$132 \quad 1284$

3823

I205

1249

$\begin{array}{ll}3771 & 547 \\ 3735 & 537 \\ 3698 & 541 \\ 3649 & 545\end{array}$

\section{7}

7656

2902

2936

10609

I976

7635

2995

3078

I0 $592 \AA$

10630 \%

I0 682

$145 \quad 1452$

3866

1448

$3907 \quad 1582$

3690

4046

572

(b) LIVB BIRTHS

Actual numbers:

1973

1974

1975

1976

$\begin{array}{ll}52.5 & 19.0 \\ 47.9 & 19.3 \\ 43.0 & 19.0 \\ 38.1 & 18.6\end{array}$

525.4

500.4

473.3

462.5

33.8

32.4

3I. 3

31.2

Projected numbers:

I98I

1986

$\begin{array}{ll}46.4 & 26.2 \\ 50.1 & 25.0\end{array}$

516.0

40.0

$618.2 \quad 48.0$

40.0
35.2
32.2
29.9

3.4

3.2

3.I

2.8

(7604

7701

8096

3472

3598

II 173

II 694

74.2

$\begin{array}{lll}617.9 & 56.2 & 674.2 \\ 583.4 & 54.9 & 638.4 \\ 548.5 & 53.4 & 601.9\end{array}$

$530.5 \quad 52.6$

583.I

$33.9 \quad 3.8$

596.3

70.0

666.3

39.7

4.2

708.0

77.2

785.2

(c) ABortions

Actual numbers:

1973

1974

1975

1976

$\begin{array}{ll}0.9 & 23.0 \\ 0.9 & 23.7 \\ 0.9 & 23.7 \\ 0.9 & 23.2\end{array}$

$30.6 \quad 34.6$

$29.8 \quad 34.1$

$28.5 \quad 32.9$

$27.0 \quad 31.5$

$\begin{array}{ll}\text { I5.3 } & 3.1 \\ \text { I4.4 } & 3.1 \\ 13.6 & 3.0 \\ \text { I1.9 } & 3.0\end{array}$

46.8

45.I

43. 1

39.8

60.7

60.9

59.6

57.7

I07.5

106.0

102.6

97.5

Projected numbers:

$\begin{array}{ll}\text { I98I } & \text { A } \\ \text { I986 } & \text { A } \\ \text { I98I } & \text { B } \\ \text { I986 } & \text { B }\end{array}$

$\begin{array}{ll}\text { I.2 } & 29.9 \\ \text { I.3 } & 30.9 \\ \text { I.3 } & 34.9 \\ \text { I.4 } & 36.1\end{array}$

$\begin{array}{ll}25.9 & 40.0 \\ 31.0 & 48.0 \\ 27.0 & 41.7 \\ 33.2 & 49.1\end{array}$

$\begin{array}{ll}13.8 & 3.9 \\ 16.2 & 4.5 \\ 16.7 & 4.5 \\ 19.6 & 5.1\end{array}$

40.9

$48.5 \quad 83.4$

$45.0 \quad 81 . \mathrm{I}$

$54.2 \quad 90.3$

$\begin{array}{ll}73.8 & \text { II } 4.7 \\ 83.4 & \text { I3I.9 } \\ 81.1 & \text { I26.I } \\ 90.3 & \text { I44.5 }\end{array}$

I 14.7

31.9

144.5

Notes-Births and abortions occurring in England and Wales to women resident there. $\mathrm{M}$ : currently married 3 women. NM: non-married women (= all others).

at about 55-56 per cent and 50 per cent respectively for the non-married aged 16-19 and 20-34;

b) that in two much smaller groups incidence rates are still rising: teenage married girls (from 1.7 to 2.3 per cent over 1973-76) and non-married women over 34 (from 47.7 to 51.7 per cent).

The age-specific and incidence rates for abortion during $1973-76$ in Table II can be used for projecting possible future trends. If nothing else were to change, then over the decade 1976-86 changes in the size and composition of the relevant age groups could by themselves generate an increase in abortions. Section (a) of Table I shows expected numbers of women in the various age groups in 1981 and 1986, derived from the most recent official population projections (OPCS ${ }^{2}$ ). By 1986 the total female population at risk will have grown by Im., or $9 \frac{1}{2}$ per cent; but in the most abortionprone group, non-married women of 20-34 (and predominantly under 25), the increase is expected too be disproportionately larger: almost 27 per cent. If in 1986 age-specific abortion rates were to remaino unchanged at the 1976 levels (cf. section (b) of Table II), there would nevertheless be 110000 o abortions as against the 97500 recorded for 1976.0 If nothing else changes, a 13 per cent increase in స్ abortions can be expected by 1986 simply in con- 0 sequence of age-group changes; and this increase would reflect no change at all in the true impact of abortion.

This estimate is, however, too simple. It assumes that pregnancy rates as well as abortion rates wouldo remain at 1976 levels. Future pregnancy rates are unpredictable. But there are good reasons for $\vec{D}$ expecting fertility - and therefore pregnancy - rates soon to turn up from the low point they reached in 1976.

The official population projections incorporate 
TABLB II* Pregnancy, births and abortion rates

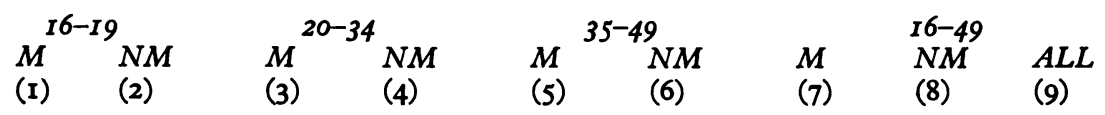

(a) BIRTHS PER IOOO WOMEN

Actual

$\begin{array}{crrrrrrrrr}\text { 1973 } & 355 & 16.0 & 139 & 28.9 & 10.6 & 6.2 & 80.2 & 19.4 & 63.5 \\ \text { 1974 } & 360 & 16.0 & 132 & 27.2 & 9.4 & 6.0 & 76.2 & 18.7 & 60.3 \\ 1975 & 318 & 15.2 & 125 & 26.0 & 8.7 & 5.7 & 71.8 & 17.8 & 56.6 \\ \text { I976 } & 287 & 14.5 & 121 & 25.0 & 8.2 & 5.1 & 69.8 & 17.1 & 54.6 \\ \begin{array}{c}\text { Projected } \\ \text { I981 }\end{array} & & & & & & & & & \\ \text { I986 } & 320 & 18.0 & 133 & 27.6 & 9.2 & 6.6 & 77.4 & 20.2 & 59.6 \\ & 350 & 18.2 & 158 & 30.3 & 9.8 & 6.6 & 87.5 & 21.5 & 67.1\end{array}$

(b) ABORTIONS PER IOOO WOMEN

Actual

\begin{tabular}{|c|c|c|c|c|c|c|c|c|c|}
\hline 1973 & 6.I & 19.4 & 8.I & 29.6 & 4.I & 5.7 & 6.1 & 20.9 & IO.I \\
\hline I974 & 6.7 & 19.5 & 7.9 & 28.7 & 3.9 & 5.8 & 5.9 & 20.7 & 10.0 \\
\hline I975 & 6.7 & 19.0 & 7.5 & 27.3 & 3.7 & 5.5 & 5.6 & 19.9 & 9.7 \\
\hline 1976 & 6.8 & I8. I & 7.0 & 25.2 & 3.3 & 5.5 & 5.2 & 18.7 & 9.1 \\
\hline \multicolumn{10}{|l|}{ rojecte } \\
\hline I98I & 8.3 & 20.6 & 6.7 & 27.6 & 3.7 & 6.8 & 5.3 & 21.3 & 10.3 \\
\hline $1986 \mathrm{~A}$ & 9.I & 22.5 & 7.9 & 30.3 & 4.0 & 7.0 & 6.0 & 23.2 & II.3 \\
\hline $1981 \mathrm{~B}$ & 9.0 & 24.0 & 7.0 & 28.8 & 4.5 & 7.9 & 5.8 & 23.4 & 11.3 \\
\hline I986 B & 9.8 & 26.2 & 8.5 & 31.0 & 4.8 & 8.0 & 6.7 & 25.1 & 12.4 \\
\hline
\end{tabular}

(c) KNOWN PREGNANCIES PER 1000 WOMEN

Actual

\begin{tabular}{|c|c|c|c|c|c|c|c|c|c|}
\hline 1973 & $36 I$ & 35.4 & I47 & 58.5 & I4.7 & II.9 & 86.2 & 40.3 & 73.7 \\
\hline 1974 & 367 & 35.5 & I40 & 55.9 & 13.3 & II.8 & 82.I & 39.4 & 70.3 \\
\hline 1975 & 325 & 34.2 & 132 & 53.3 & 12.4 & II.2 & 77.5 & 37.7 & 66.3 \\
\hline 1976 & 295 & 32.6 & I28 & 50.2 & II. 5 & I0.6 & 75.0 & 35.8 & 63.7 \\
\hline \multicolumn{10}{|l|}{ ojected } \\
\hline I981 A & 328 & 38.6 & I40 & 55.2 & I2.9 & 13.5 & 82.7 & 4I.4 & 69.9 \\
\hline 1986 & 359 & 40.6 & I66 & 60.7 & I3.8 & I3.6 & 93.4 & 44.6 & 78 \\
\hline I98I & 329 & 42.0 & 140 & 56.4 & 13.7 & I4.5 & 83.3 & 43.5 & 70.9 \\
\hline I986 B & 360 & 44.4 & I67 & $6 \mathrm{r} .4$ & I4.7 & 14.5 & 94.I & 46.6 & 79.5 \\
\hline
\end{tabular}

(d) ABORTIONS \% OF KNOWN PREGNANCIES

Actual

\begin{tabular}{|c|c|c|c|c|c|c|c|c|c|}
\hline I973 & I. 7 & 54.8 & 5.5 & 50.6 & 23.4 & $47 \cdot 7$ & 7.0 & 51.9 & 13.8 \\
\hline 1974 & I.8 & 55.1 & 5.6 & 51.3 & 29.0 & 49.2 & 7.2 & 52.6 & 14.2 \\
\hline I975 & 2.I & 55.5 & 5.7 & 51.2 & 29.7 & 49.2 & 7.3 & 52.7 & 14.6 \\
\hline I976 & 2.3 & 55.5 & 5.5 & 50.2 & 28.5 & 51.7 & 7.0 & 52.3 & 14.3 \\
\hline \multicolumn{10}{|l|}{ rojected } \\
\hline I98I A & 2.5 & 53.3 & 4.8 & 50.0 & 29.0 & 50.6 & 6.4 & 51.3 & 14.7 \\
\hline 1986 & 2.5 & 55.3 & 4.8 & 50.0 & 29.0 & 51.7 & 6.4 & 51.9 & 14.4 \\
\hline r98I & 2.7 & 57.1 & 5.0 & 51.0 & 33.0 & 54.2 & 7.0 & 53.7 & 15.9 \\
\hline r986 & 2.7 & 59.1 & 5.1 & 50.6 & 33.0 & 54.8 & 7.1 & 53.9 & 15.5 \\
\hline
\end{tabular}

*A thoroughly refined analysis would establish the number of known pregnancies more precisely a) by counting stillbirths as well as live births, and b) by adding to the births and stillbirths occurring in a year the abortions occurring, not in the same period, but six months earlier (ie resulting from the same 'cohort' of pregnancies). The effect of (a) is negligible. Neglect of (b) - inevitable without unpublished data - is unlikely to distort the picture of long-term trends.

the assumption that fertility will not remain static but will rise until by the mid-r 980 s it reaches replacement level - i.e. suffices to yield completed families averaging 2.1 children per woman (as against about 1.7 for 1976 fertility). 'A simple assumption of replacement-level fertility may be regarded as the most appropriate basis for a longterm projection, particularly when the available 
evidence about the intentions of young married women at the present time points to average family size somewhere in that neighbourhood' (OPCS ${ }^{2}$ ). The projected births in Table I, section (b), and the fertility rates in Table II, section (a), are derived from the trends assumed in the official projections.

\section{The hypotheses}

If fertility moves in this way and the pattern of births is as shown, it becomes possible to estimate future trends in known pregnancies by applying differing assumptions about abortion incidence rates. The two hypotheses explored in this note are that abortion incidence rates a) remain stable at about the 1976 level or b) increase appreciably. The key assumptions are:

Abortions \% of known pregnancies

\begin{tabular}{llll}
\hline & $\begin{array}{l}\text { I976 } \\
\text { actual }\end{array}$ & $A$ & $B$ \\
\hline I6-19 & 29.8 & 30.0 & 33.3 \\
$20-34$ & 10.6 & 10.6 & I1.0 \\
$35-49$ & 31.3 & 32.0 & 36.0 \\
$20-34$ & 50.2 & 50.0 & 51.0 \\
\hline
\end{tabular}

Given these parameters, rates for all other groups were worked out by a process of 'best fitting'.

The outcome, in section (c) of Table A, is striking. On hypothesis $A$, assuming 1976 fertility as well as no change in the true impact of abortion, age-group effects alone would raise the number of abortions by I3 per cent to I I0,000 by I 986 . If, however, fertility were to rise moderately up to replacement level, ${ }^{*}$ then the abortion total would grow to 132000 - an increase of 35 per cent (matching a 35 per cent increase in births).

Thus, over the next ten years changes in fertility and pregnancy rates may be expected to influence the number of abortions much more than changes in the size of relevant female age groups. And an increase in abortions among women over 15 from 97500 a year to anywhere between I 10000 and I32000 could be entirely compatible with no increase at all in the true impact of abortion, in terms of the proportions of pregnancies terminated.

Hypothesis $B$ allows for some increase in the incidence of abortions in all groups, up to the levels shown for 1986 in the last line of section (d) of

\footnotetext{
*Such an increase would be moderate. Fertility measured in terms of the implied average completed family size ('total period fertility rate') rose from 2.14 in 195 I to 2.94 in 1964 , then dropped to 2.02 in 1973 and 1.72 in 1976 . The corresponding net reproduction rates were I.00 ( $\equiv$ exact generation replacement), I.37, 0.96 and about $0.82\left(\mathrm{OPCS}^{3}\right)$.
}

Table B - for example from $55 \frac{1}{2}$ to 59 per cent $\stackrel{\mathbb{D}}{2}$ among non-married girls of $16-19$ and from $28 \frac{1}{2 F}$ to 33 per cent among married women over 34 . On this hypothesis the number of abortions could? increase by nearly 50 per cent to 145000 .

On both hypotheses the established tendency for the non-married to obtain more abortions than the married would be intensified. The non-marrieck share of abortions rose from 57 per cent in 1973 to⿸丆 59 per cent in 1976 , and may rise to 63 per cent in 1986, with girls of I6-19 accounting for 23-25 pefs cent of the total, against 21 per cent in 1973 . This $\vec{D}$ shift would come about chiefly because, as already noted, the most abortion-prone group, non $\frac{\omega}{\sigma}$ married women aged 20-34 (with a pregnancy rate of 50 per 1000 women, with half the pregnancies being terminated), is also the group which wilf experience the most disproportionate numerica $\vec{A}$ enlargement.

How plausible are these hypotheses? It is no implausible to expect some increased resort t $\overrightarrow{0}$ abortion among unmarried girls in their 'teens, an possibly also among teenage wives - all beginners in adult life, sex and the arts of contraception. It may also be plausible to expect some increase amono the non-married over 34 . To that extent - but no further - hypothesis $B$ may be justified. But for ald the other groups there are no current indications of any increase at all, and a good many indications tha reduced rather than increased resort to abortion i⿱ more likely. Thus it is highly likely that couplea who have completed their wanted families wif turn increasingly to sterilization of husband or wifes so that abortion rates and incidence among marrie women over 30 or 35 are more likely to fall than t remain stable (hypothesis $A$ ) or to rise (hypothes $B){ }^{*}$ The incidence of abortion among all adult agథ groups, and eventually perhaps also among teen? agers, is also more likely to fall as knowledge an practice of reliable contraception become more firmly established, now that the National Health Service has assumed full responsibility for famil욤 planning services, for the unmarried as well as th married, and over 90 per cent of general prac@. titioners are undertaking to give advice.

It may be fairly concluded that hypothesis $B$ is not realistic, and that the hypothesis $A$ estimates based on continuance of the existing incidence of abortion, is more likely to overstate than to under state future trends. They are best regarded maxima not likely to be attained.

\section{Under age pregnancies}

Excluded from the foregoing review are girls und $\stackrel{\mathbb{P}}{\mathbb{P}}$ I6. The gist of the little information published abou them is summarised on the next page.

* Only one fifth of children are now born to women age 30 and over, against three fifths in mid-Victorian times. 


\begin{tabular}{|c|c|c|c|c|c|}
\hline & & & ates per Io & oo girls & \\
\hline & Ages & Births & Abortions & $\begin{array}{l}\text { Known } \\
\text { pregnancies }\end{array}$ & $\begin{array}{l}\% \text { of known } \\
\text { pregnancies }\end{array}$ \\
\hline I973 & $\begin{array}{c}\mathrm{I} 2-\mathrm{I} 4 \\
\mathrm{I} 5\end{array}$ & $\begin{array}{l}0.29 \\
3.75\end{array}$ & $\begin{array}{l}0.75 \\
6.39\end{array}$ & $\begin{array}{r}1.04 \\
10.14\end{array}$ & $\begin{array}{l}72 \\
63\end{array}$ \\
\hline & 12-I5 & 1.16 & 2.16 & 3.32 & 65 \\
\hline I975 & $12-15$ & 1.00 & $2.4 \mathrm{I}$ & $3.4 \mathrm{I}$ & 71 \\
\hline I976 & 12-I5 & 0.79 & 2.24 & 3.03 & 74 \\
\hline
\end{tabular}

In this school-girl group the bulk of births and abortions occur among 15-year-olds and most of the rest among 14-year-olds. Even among girls of I5 pregnancies are, fortunately, rare: about 99 per cent do not become pregnant at that age; and it is not clear whether there is any tendency for the incidence of pregnancy to increase.

What is clear, taking the age group $12-15$ as a whole, is that when pregnancy does occur it is now normally and increasingly ended by abortion. The abortion incidence rate rose from 65 per cent in 1973 to 74 per cent in 1976 . This is a trend which may be expected to progress further, since it appears to be favoured by the climate of opinion. By 1986 at least 80 per cent, and possibly 90 per cent, of these premature pregnancies may be terminated.
In 1976 three girls per 1000 in the $12-15$ age group were pregnant and 74 per cent of their pregnancies were terminated. The outcome was 3500 abortions and 1200 births. If in 1986 the pregnancy rate is the same, the outcome will be:

a) if 80 per cent are terminated: 3250 abortions and 800 births

b) if 90 per cent are terminated: 3650 abortions and 400 births.

Although there are no current indications that this may happen, if the pregnancy rate were to rise to 3.5 per 1000 (it did reach 3.4 in 1975), and if the termination rate rose to 90 per cent, then in 1986 there could be 4250 abortions and 470 births occurring among girls aged 12-15.

\section{References}

'Tietze, C and Murstein, M C (1975). Induced Abortion: 1975 Factbook, Reports on Population/Family Planning, no. 14, 2nd ed., Population Council, New York.

2Office of Population Censuses and Surveys (1977). Population Projections 1975-2015, Series PP2, no. 7, HMSO, London.

${ }^{3}$ Office of Population Censuses and Surveys (1977). Birth Statistics 1974, England and Wales, Series FMI, no. I, HMSO, London, Table I.4. 